\title{
Conhecimento das puérperas sobre a triagem neonatal
}

Puerperal women's knowledgment about neonatal screening

Conocimiento de puerperas sobre el examen neonatal

Beatriz Gabriela Ferreira da Silva CUNHA ${ }^{1}$

Larissa Brazolotto FERREIRA ${ }^{2}$

${ }^{1}$ Graduada em Enfermagem pela Universidade Paulista, Campus Araçatuba, 16018-555 Araçatuba - SP, Brasil

${ }^{2}$ Graduada em Enfermagem pela Universidade Paulista, Campus Araçatuba, Mestre em Ciências Fisiológicas pelo Programa de PósGraduação Multicêntrico em Ciências Fisiológicas,

Doutoranda do Programa de Tocoginecologia FMB/UNESP

Docente do Curso Enfermagem pela Universidade Paulista Campus Araçatuba, 16018-555 Araçatuba - SP, Brasil

\section{Resumo}

Introdução: A palavra triagem significa separar, escolher, e em saúde pública, consiste em separar uma certa população em dois grupos, sendo um constituído por aqueles com uma determinada patologia, e outro por aqueles que não à possuem. $A$ triagem neonatal é uma ação preventiva, realizada através de exames feitos nos recém-nascidos, que permite realizar diagnóstico de diversas doenças, a tempo de interferir em seu curso. Através do tratamento precoce, visando a diminuição ou eliminação de sequelas. Objetivo: Foi verificar o nível de conhecimento das puérperas sobre a triagem neonatal, se elas receberam informações acerca dos exames que devem ser realizados no recém-nascido, doenças diagnosticadas e período de realização. Casuística e Métodos: Tratou-se de uma pesquisa de campo, de caráter exploratório, com delineamento transversal e prospectivo com análise quantitativa descritiva dos dados. Para isto, foram entrevistados 40 puérperas. Resultados: A média de idade encontrada foi de 29 anos. 50,0\% das participantes possuíam ensino médio completo, 60,0\% trabalhavam, e total as entrevistadas realizaram consulta de pré-natal. $80,0 \%$ das entrevistadas relataram ter recebido informações sobre os exames a serem realizados no recém-nascido, porém quando questionadas sobre quais seriam esses exames apenas $25,0 \%$ das entrevistadas souberam informar. Conclusão: Os resultados obtidos por esta pesquisa apontam uma baixa compreensão das puérperas acerca da Triagem Neonatal. Nos mostrando o quanto é importante que o enfermeiro e a equipe multiprofissional trabalhem esse tema com as gestantes em cada consulta de pré-natal, esclarecendo o significado e a importância da Triagem Neonatal.

Descritores: Triagem Neonatal; Recém-Nascido; Parto; Cuidado Pré-Natal; Promoção da Saúde.

\section{Abstract}

Introduction: The word screening means to separate, to choose, and in public health, to separate a certain population into two groups, one consisting of those with a particular pathology, and another by those who do not have it. Neonatal screening is a preventive action, performed through newborn examinations, which allows the diagnosis of various diseases in time to interfere with their course. Through early treatment, aimed at reducing or eliminating sequelae. Objective: It was to verify the level of knowledge of the mothers abount neonatal screening, if they received information about the tests that should be performed on the newborn, diagnosed diseases and period of performance. Casuistic and Methods: This was an exploratory field research with a prospective cross-sectional desing with descriptive quantitative data analysis. For this, 40 postpartum women were interviewed. Results: The average age found was 29 years. 50,0\% of the participants had completed high school, $60,0 \%$ worked, and the total interviewed attended prenatal consultation. 80,0\% of the interviewees reported having received information about the tests to be performed on the newborn, but when asked what these tests would be, only $25,0 \%$ of the interviewees were able to inform. Conclusion: The results obtained by this research indicate a low understanding of the mothers about the Neonatal Screening. Showing how important it is for nurses and the multiprofessional team to work on this theme with pregnant women at each prenatal visit, clarifying the meaning and importance of Neonatal Screening.

Descriptors: Neonatal Screening; Infant, Newborn; Parturition; Prenatal Care; Health Promotion.

\section{Resumen}

Introducción: La palabra triaje significa separar, elegir, y en salud pública consiste en separar una determinada población en dos grupos, uno formado por los que padecen una determinada patología y el otro por los que no la padecen. El cribado neonatal es una acción preventiva, realizada a través de exámenes realizados a los recién nacidos, que permite el diagnóstico de diversas enfermedades, a tiempo de interferir en su curso. Mediante un tratamiento precoz, dirigido a reducir o eliminar las secuelas. Objetivo: Verificar el nivel de conocimiento de las puérperas sobre el cribado neonatal, si recibieron información sobre las pruebas que se deben realizar al recién nacido, las enfermedades diagnosticadas y el período de realización. Material y Métodos: Se trata de una investigación de campo exploratoria, con un diseño transversal y prospectivo con análisis descriptivo de datos cuantitativos. Para ello se entrevistó a 40 puérperas. Resultados: La edad media encontrada fue de 29 años. El 50,0\% de las participantes había finalizado el bachillerato, el 60,0\% trabajaba y todas las entrevistadas tenían consulta prenatal. El $80,0 \%$ de los entrevistados refirió haber recibido información sobre las pruebas a realizar al recién nacido, pero cuando se les preguntó cuáles serían estas pruebas, solo el 25,0\% de los entrevistados supo informar. Conclusión: Los resultados obtenidos por esta investigación indican un bajo conocimiento de las mujeres en el posparto sobre el cribado neonatal. Mostrándonos lo importante que es para las enfermeras y el equipo multidisciplinario trabajar este tema con la gestante en cada consulta prenatal, aclarando el significado e importancia del Tamizaje Neonatal.

Descriptores: Tamizaje Neonatal; Recién Nascido; Parto; Atención Prenatal; Promoción da la Salud.

INTRODUÇÃO

A palavra triagem significa separar, escolher, e em saúde pública, indica a ação primária, visa separar uma população alvo em dois grupos, sendo um constituído por aqueles com uma determinada patologia, e outro por aqueles que não à possuem ${ }^{1}$.

Atendendo com o estabelecido pela Lei 8.069, de 13 de julho de 1990, toda criança tem o direito à vida e à saúde, desde a gestação até o nascimento e o desenvolvimento sadio e harmonioso, em condições dignas de existência, sendo assegurado através de políticas sociais públicas, atendendo com os princípios da universalidade, equidade e integralidade ${ }^{2}$.

Em 1976, a Associação de Pais e Amigos dos Excepcionais (APAE) de São Paulo teve a iniciativa de trazer para o Brasil o teste do pezinho, o que posteriormente deu origem à 
lei que garante o direito de todo recém-nascido realizar o teste, por meio do Programa Nacional de Triagem Neonatal ${ }^{3}$.

O teste do pezinho deve ser realizado por um profissional de enfermagem treinado e qualificado, entre o $3^{\circ}$ e $5^{\circ}$ dia de vida do bebê, não devendo ultrapassar o $28^{\circ}$ dia de vida, é possível identificar seis doenças, sendo elas a fenilcetonúria, hipotireoidismo congênito, doença falciforme e outras hemoglobinopatias, fibrose cística, hiperplasia adrenal congênita e deficiência de biotinidase ${ }^{4}$. São doenças que necessitam de tratamento precoce e acompanhamento multiprofissionais por toda a vida, pois sem esses cuidados elas podem gerar danos neurológicos irreversíveis ${ }^{5}$.

As informações fornecidas pelos profissionais que vão atuar durante o pré-natal, parto e pós-parto são extremamente importantes, pois vão esclarecer dúvidas quanto à realização dos testes, com o propósito de evidenciar os benefícios da adoção de comportamentos preventivos e de promoção de saúde ${ }^{1}$.

Foram realizadas entrevistas com 200 pais e cuidadores no momento da coleta do teste do pezinho, onde realizaram perguntas de forma simplificada a respeito do teste, 170 desses entrevistados tinham conhecimento do que se tratava o teste sendo que 30 deles não tinham conhecimento algum a respeito, apenas 52 dos entrevistados souberam dizer, em caso de alteração seria necessário acompanhamento com especialistas e tratamento ${ }^{1}$.

O teste do reflexo vermelho ou teste do olhinho é um exame simples, rápido e indolor, deve ser feito em todos os recém-nascidos antes da alta hospitalar, e ser repetido nos dois primeiros anos a cada seis meses ${ }^{6}$. Nele consiste em, quando um feixe de luz ilumina 0 olho do bebê ele reflete de volta um reflexo vermelho, significa que o eixo óptico está livre, sem nenhum obstáculo a entrada e saída da luz ${ }^{7}$. O teste do olhinho pode evitar até $80 \%$ dos casos de cegueira, pois ele possibilita a identificação e tratamento precoce de várias doenças entre elas a catarata congênita, retinopatia de prematuridade, glaucoma congênito, retinoblastoma ${ }^{6}$.

Estudo realizado com 367 puérperas à respeito do testes do olhinho onde constatou que 220 delas já ouviram falar sobre o testes, sendo que apenas 9 souberam falar de sua finalidade, 86 responderam erroneamente e 125 não sabiam sua finalidade ${ }^{8}$.

O teste do coraçãozinho ou oximetria de pulso trata-se de um exame simples, barato, rápido e indolor que possibilita a identificação precoce de cardiopatias congênitas críticas ${ }^{9}$. Nas cardiopatias congênitas críticas ocorre a mistura da circulação sistêmico com a pulmonar levando a redução da saturação de oxigênio ${ }^{10}$. $O$ teste deve ser feito em todos recém-nascidos com idade gestacional superior a 34 semanas, deve ser realizado entre 24-48 horas antes da alta hospitalar, devendo ser feito com oxímetro de pulso com sensor neonatal ${ }^{9}$. O teste é positivo se a saturação for menor que $95 \%$ ou a diferença entre os membros forem $3 \%$ ou mais, caso tenho alteração o teste deve ser repetido após uma hora, permanecendo alterado deve ser realizado ecocardiograma em até 24 horas $^{9}$.

De acordo com a Lei $n^{\circ} 12.303$, de 02 de ago. de 2010, é obrigatório em todos hospitais ou maternidades do Brasil a realização do exame denominado Emissões Otoacústicas Evocadas, conhecido como teste da orelhinha ${ }^{11}$. O teste é rápido e indolor, deve ser realizado em todos recém-nascidos antes de receberem alta hospitalar entre 24-48 horas de vida, o exame possibilita diagnóstico e tratamento precoce de problemas auditivos ${ }^{12}$. O exame consiste na colocação de um fone acoplado a um computador na orelha do bebê que emite sons de fraca intensidade e recolhe as respostas que a orelha interna do bebê produz $^{13}$. Caso o resultado seja insatisfatório deve ser repetido imediatamente, se o resultado permanecer, deve ser feito o Potencial Evocado Auditivo de Tronco Encefálico, e realizar o reteste em 30 dias, com a identificação da perda auditiva deve ser realizado avaliação otorrinolaringológica completa ${ }^{13}$.

Em estudo com 75 mães que compareceram para a realização da Triagem Neonatal Auditiva, onde foi possível identificar que 58 delas souberam que a Triagem Neonatal Auditiva é a maneira de identificar a deficiência auditiva precocemente, 6 não souberam falar e 11 tiveram respostas parcialmente corretas, quando questionadas quanto as informações fornecidas 64 mães disseram ser suficiente para compreensão do exame ${ }^{14}$.

De acordo com a lei 13.002 , de 20 de junho de 2014, é obrigatória a realização da avaliação do frênulo da língua de todo bebê nascido em território nacional ${ }^{15}$. A língua possui uma pequena prega de membrana mucosa em sua parte inferior, denominada de frênulo da língua, que se conecta ao assoalho da boca, essa membrana pode limitar o movimento da língua, a sucção e deglutição, são funções relacionadas com a amamentação, sendo assim qualquer fator que interfira nos movimentos da língua dificulta a amamentação ${ }^{16}$. O teste deve ser feito por um profissional da área da saúde 
habilitado, onde ele deve elevar a língua e observar se ela está presa, avaliar o bebê durante a amamentação e o choro, o exame deve ser realizado o mais cedo possível, na maternidade ou hospital ${ }^{17}$.

Em estudo com 427 gestantes que fizeram pré-natal em um hospital escola do sul do Brasil foi possível analisar que um número baixo de gestantes conhecia o Protocolo de Avaliação do Frênulo da Língua em Bebê, sendo que apenas $18 \%$ já ouviram falar sobre o assunto, 93\% não tinham conhecimento sobre a finalidade, $92 \%$ não sabiam do período de realização e $92 \%$ não souberam falar sobre o procedimento de frenotomia, sendo assim esses fatores demonstram a falta de conhecimento deste grupo de mulheres quanto a este assunto $^{18}$.

Por se tratar de protocolos, assim como várias ações de saúde, muitas vezes os exames são realizados nos recém-nascidos sem que as puérperas saibam do que se trata ou dos benefícios que o diagnóstico precoce pode proporcionar. Com base no exposto, o objetivo deste trabalho foi verificar qual o conhecimento das puérperas quanto a esses testes.

MATERIAL E MÉTODO

Tratou-se de uma pesquisa de campo, de caráter exploratório, com delineamento transversal e prospectivo com análise quantitativa descritiva dos dados. O estudo teve como o objetivo verificar o conhecimento das puérperas sobre os testes de triagem neonatal, se elas receberam informações acerca dos exames que devem ser realizados no recémnascido, doenças diagnosticadas e período de realização. Para isto, foram entrevistados 40 puérperas.

Foram adotados como critérios de inclusão, mulheres que se encontravam durante o período de puerpério, com idade superior a 18 anos e que aceitaram participar da pesquisa. Foram excluídos da pesquisa: mulher fora do período puerperal, com idade inferior a 18 anos e que não aceitaram participar da pesquisa. $A$ coleta de dados ocorreu após aprovação do Comitê de Ética e Pesquisa, parecer no 3.425.084, e aprovação pelo sujeito da pesquisa por meio da anuência no Termo de Consentimento Livre Esclarecido, mantendo sigilo sobre as informações obtidas dos sujeitos, conforme Resolução №466/2012, da Comissão Nacional de ética e Pesquisa (CONEP) vinculada ao Ministério da Saúde.

Foi utilizado para a coleta de dados, um questionário semiestruturado no qual só foram aplicados nos sujeitos da pesquisa mediante apresentação explícita da pesquisa bem como dos propósitos de estudo. A aplicação do questionário ocorreu de forma individual, com resposta espontânea para análise das informações investigadas, dentre elas socioeconômicas, tais como: idade, grau de escolaridade, estado civil, renda familiar, além de questões relacionadas, especificamente, a triagem neonatal. A análise dos dados foi realizada por meio do programa Microsoft Excel 2007 e as variáveis do estudo foram apresentadas por meio da estatística descritiva evidenciando a distribuição relativa (\%) e absoluta (n) dos dados e posteriormente apresentada na forma de gráficos e tabelas.

RESULTADOS

A pesquisa foi realizada com 40 puérperas, que frequentam a Unidade Básica de Saúde "Dr. Alfredo Dantas de Souza" na cidade de Araçatuba - SP, com o objetivo de identificar o conhecimento das puérperas em relação a Triagem Neonatal.

A média de idade foi de 29 anos. Os dados sociodemográficos estão descritos na Tabela 1, onde observamos que $50,0 \%$ das participantes possuem ensino médio completo, $60,0 \%$ trabalham, com renda familiar em torno de um a três salários mínimos; $75,0 \%$ das puérperas são casadas e $77,5 \%$ brancas. Entre as entrevistadas $37,5 \%$ são católicas, $55,0 \%$ evangélicas.

$\mathrm{Na}$ tabela 1 podemos observar também que $40,0 \%$ é mãe pela primeira vez, $55,0 \%$ tem de 2 a 3 filhos e 5,0\% tem de 3 a 4 filhos. Todas entrevistadas realizaram consultas de pré-natal.

Tabela 1. Distribuição das puérperas participantes da pesquisa segundo os dados sociodemográficos e informações gerais. Araçatuba- SP, Brasil - 2019

\begin{tabular}{|c|c|c|}
\hline Dados Sociodemográficos & $\mathbf{N}$ & $\%$ \\
\hline \multicolumn{3}{|l|}{ Escolaridade } \\
\hline Fundamental Incompleto & 2 & 5,0 \\
\hline Fundamental Completo & 2 & 5,0 \\
\hline Ensino Médio Incompleto & 11 & 27,5 \\
\hline Ensino Médio Completo & 20 & 50 \\
\hline Ensino Superior Incompleto & 1 & 2,5 \\
\hline Ensino Superior Completo & 4 & 10 \\
\hline \multicolumn{3}{|l|}{ Trabalha } \\
\hline Sim & 24 & 60 \\
\hline Não & 16 & 40 \\
\hline \multicolumn{3}{|l|}{ Renda Familiar* } \\
\hline 1 salário mínimo & 13 & 32,5 \\
\hline 1 a 3 salários mínimos & 24 & 60 \\
\hline 3 a 5 salários mínimos & 3 & 7,5 \\
\hline \multicolumn{3}{|l|}{ Estado Civil } \\
\hline Solteira & 9 & 22,5 \\
\hline Casada & 30 & 75 \\
\hline Divorciada & 1 & 2,5 \\
\hline \multicolumn{3}{|l|}{ Etnia } \\
\hline Branco & 31 & 77,5 \\
\hline Negro & 9 & 22,5 \\
\hline \multicolumn{3}{|l|}{ Religião } \\
\hline Católica & 15 & 37,5 \\
\hline Evangélica & 22 & 55,0 \\
\hline Outras & 3 & 7,5 \\
\hline \multicolumn{3}{|l|}{ Número de filhos } \\
\hline 1 filho & 16 & 40 \\
\hline 2 a 3 filhos & 22 & 55 \\
\hline 3 a 4 filhos & 2 & 4 \\
\hline \multicolumn{3}{|l|}{ Realizou Pré-Natal } \\
\hline Sim & 40 & 100 \\
\hline Não & 0 & 0 \\
\hline
\end{tabular}


O gráfico 1, aponta que, $65,0 \%$ das puérperas participantes da pesquisa conhecem apenas alguns dos exames que devem ser feitos no recém-nascido, $10,0 \%$ não sabem quais exames são feitos.

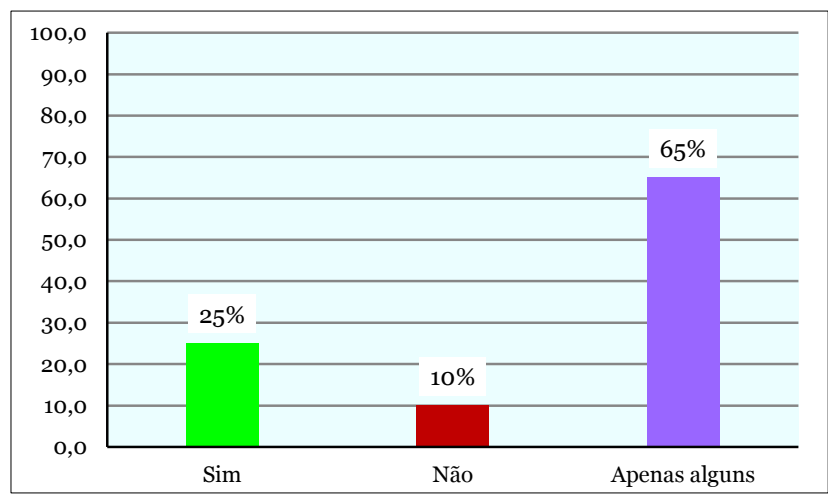

Gráfico 1. Distribuição das puérperas participantes da pesquisa segundo o conhecimento dos exames a serem feitos no recémnascido. Araçatuba- SP, Brasil - 2019

De acordo com o gráfico 2 é possível analisar que, $80,0 \%$ das puérperas participantes da pesquisa disseram ter receberam informações sobre os testes que devem ser realizados no recém-nascido; $85,0 \%$ delas conhecem o teste do olhinho, $80,0 \%$ conhecem o teste da orelhinha, já os testes da linguinha e do coraçãozinho são conhecidos por um número menor de puérperas sendo $47,5 \%$ e $45,0 \%$ respectivamente.

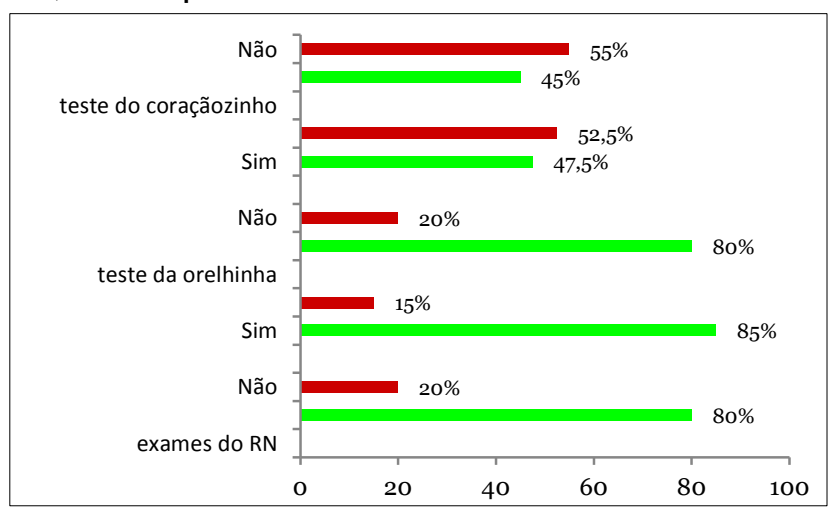

Gráfico 2. Distribuição das puérperas participantes da pesquisa segundo ter recebido informações dos profissionais de saúde sobre os exames da Triagem Neonatal. Araçatuba- SP, Brasil - 2019

Já no gráfico 3 é possível observar que $40,0 \%$ das puérperas disseram não ter recebido informações suficientes durante o pré-natal para compreender os exames que devem ser realizados no recém-nascido.

De acordo com o gráfico $4,87,5 \%$ das puérperas participantes da pesquisa conhecem a forma correta de realizar o teste do pezinho.

De acordo com o gráfico $5,80,0 \%$ das puérperas participantes da pesquisa sabem quando deve ser realizado o teste do pezinho e $10,0 \%$ não sabe; $7,5 \%$ disseram que não existe data definida para ser realizado e $2,5 \%$ disseram que pode ser realizado em qualquer momento até o bebê completar um ano.

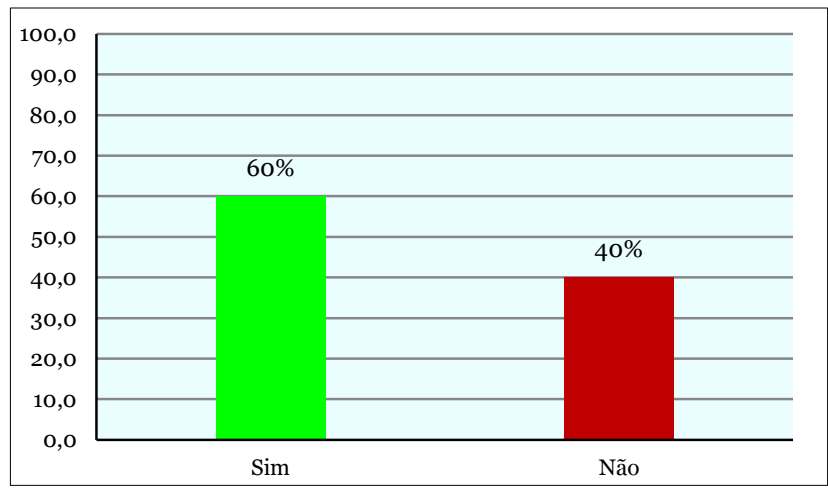

Gráfico 3 - Distribuição das puérperas participantes da pesquisa segundo ter recebido informações suficientes para compreender os exames. Araçatuba- SP, Brasil - 2019

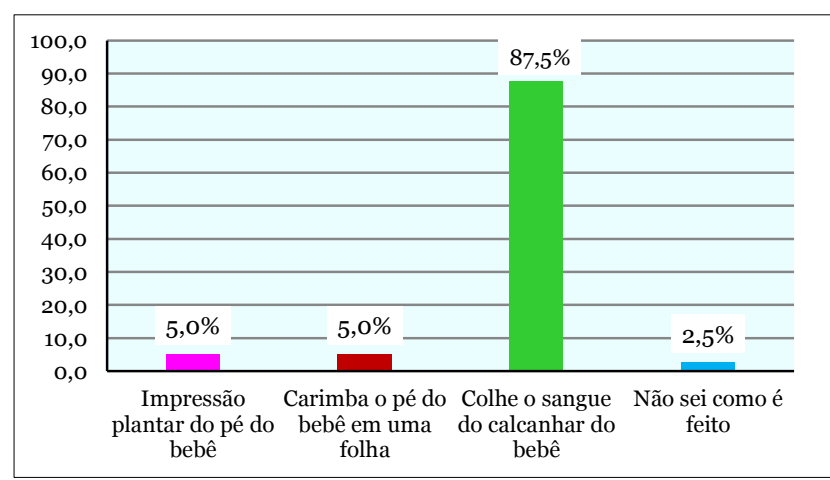

Gráfico 4. Distribuição das puérperas participantes da pesquisa segundo o conhecimento de como é feito o teste do pezinho. Araçatuba- SP, Brasil - 2019

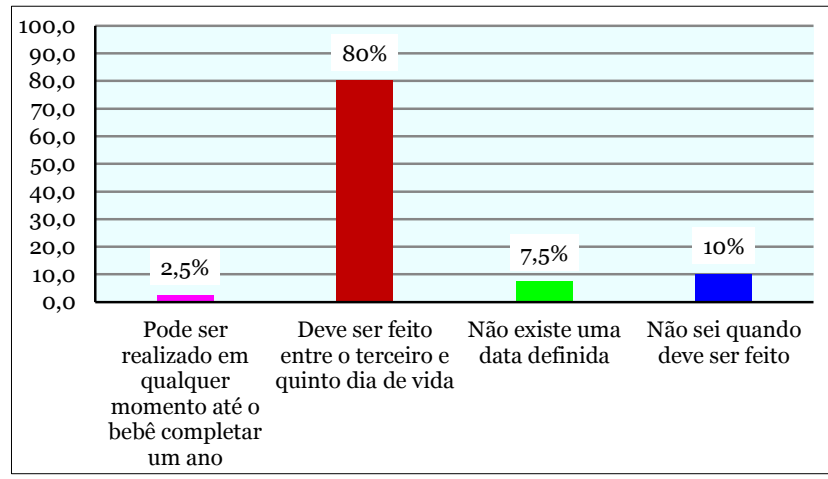

Gráfico 5. Distribuição das puérperas participantes da pesquisa segundo o conhecimento de quando deve ser realizado o teste do pezinho. Araçatuba- SP, Brasil - 2019

É possível avaliar que, $57,5 \%$ das puérperas participantes da pesquisa sabem a finalidade do teste do pezinho, enquanto $32,5 \%$ delas têm informações equivocadas e $10,0 \%$ as desconhecem, conforme aponta o gráfico 6 .

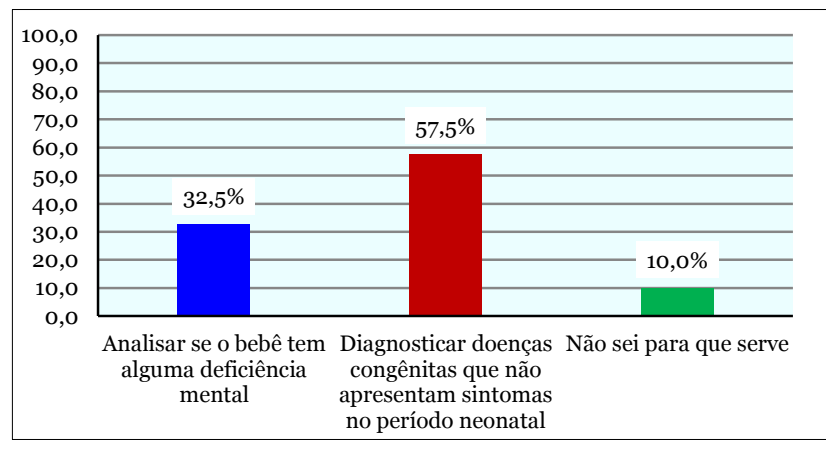

Gráfico 6. Distribuição das puérperas participantes da pesquisa segundo o conhecimento sobre a finalidade do teste do pezinho. Araçatuba- SP, Brasil - 2019 
Conforme o gráfico 7 aponta, 92,5\% das puérperas participantes da pesquisa sabem 0 que deve ser feito caso o teste do pezinho dê alterado.

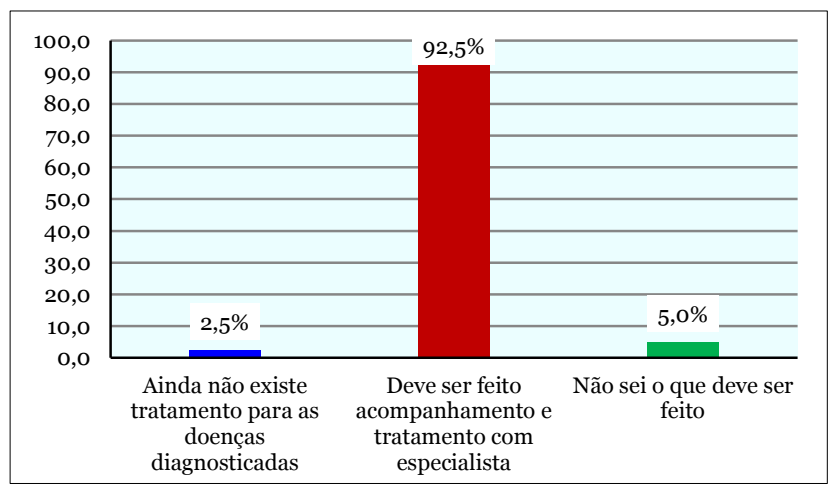

Gráfico 7. Distribuição das puérperas participantes da pesquisa segundo o conhecimento sobre o que deve ser feito caso o teste dê alterado. Araçatuba- SP, Brasil - 2019

Segundo o gráfico $8,37,5 \%$ não sabem a finalidade do teste do olhinho e $15,0 \%$ não soube informar.

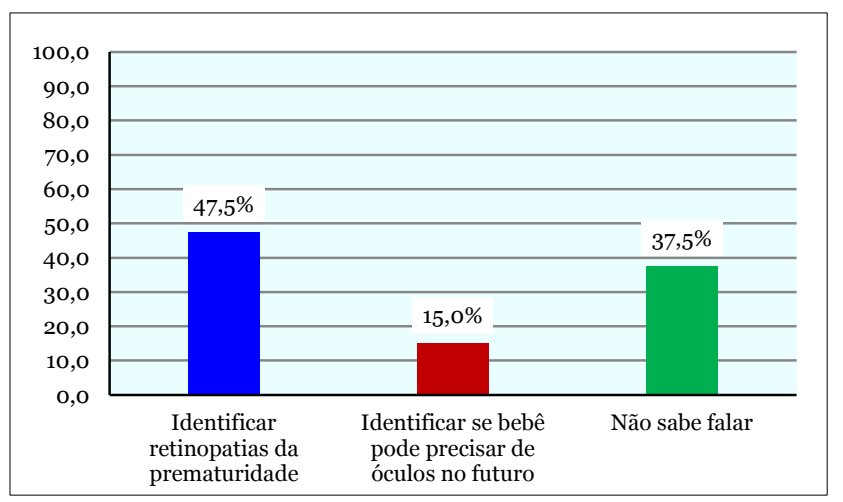

Gráfico 8. Distribuição das puérperas participantes da pesquisa segundo o conhecimento sobre a finalidade do teste do olhinho. Araçatuba- SP, Brasil - 2019

De acordo com o gráfico 9, quando questionado sobre a finalidade do teste da orelhinha, 30,0\% das puérperas não sabem do que se trata e $12,5 \%$ não tem conhecimento quanto ao teste.

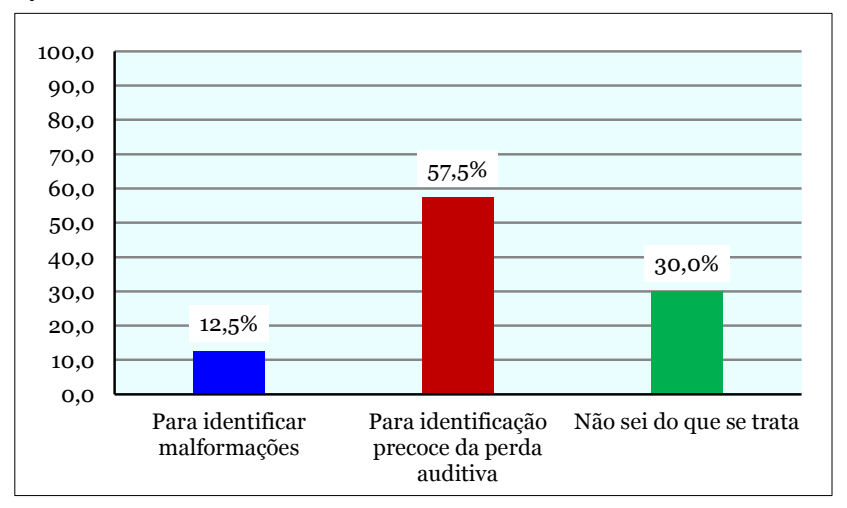

Gráfico 9. Distribuição das puérperas participantes da pesquisa segundo o conhecimento sobre a finalidade do teste da orelhinha. Araçatuba- SP, Brasil - 2019

É possível avaliar no gráfico 10 que $80,0 \%$ das puérperas participantes da pesquisa não sabem como é feito o teste da linguinha, $12,5 \%$ responderam a alternativa que não se refere à maneira correta de realizar o exame, demonstrando o conhecimento errado quanto ao teste.

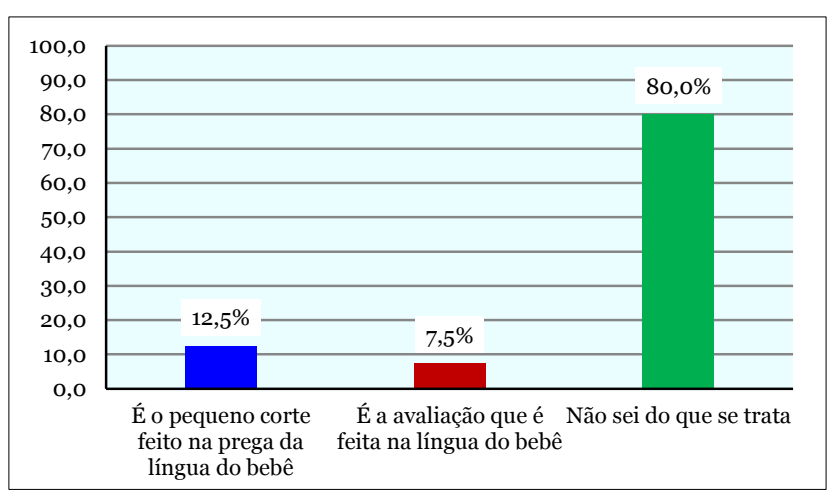

Gráfico 10. Distribuição das puérperas participantes da pesquisa segundo o conhecimento sobre a finalidade do teste da linguinha. Araçatuba- SP, Brasil - 2019

Segundo o gráfico $11,55,0 \%$ das puérperas participantes da pesquisa não sabem qual a finalidade do teste do coraçãozinho, enquanto $10,0 \%$ e 5,0\% têm informações errada quanto à finalidade do teste.

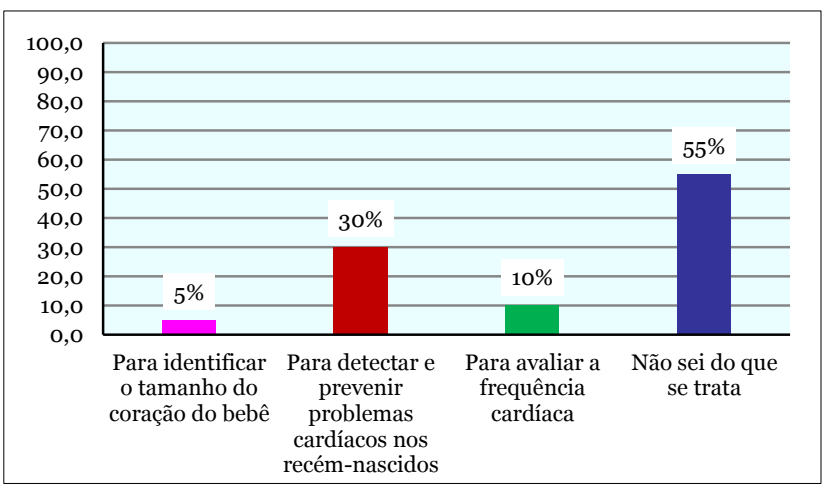

Gráfico 11. Distribuição das puérperas participantes da pesquisa segundo o conhecimento sobre qual a finalidade do teste do coraçãozinho. Araçatuba- SP, Brasil - 2019

DISCUSSÃO

Este estudo teve como objetivo verificar através de entrevistas com puérperas, se as mesmas tem conhecimento sobre os exames que compõe a triagem neonatal. A população do estudo foi composta por 40 puérperas, com idade média de 29 anos, onde $50,0 \%$ das entrevistadas concluíram ensino médio, apenas 10,0\% concluíram ensino superior, 2,5\% não concluiu ensino superior, sendo possível observar que $37,5 \%$ das entrevistadas apresentam um baixo nível de escolaridade. Em estudos semelhantes realizados com mulheres com baixa escolaridade foi possível observar dificuldade em assimilar os exames feitos no recém-nascido ${ }^{18-20}$. A maioria das puérperas $(60,0 \%)$ trabalham, com renda familiar de um a três salários mínimos, sendo que 32,5\% relatam ter renda de até um salário mínimo por mês, em pesquisa feita em 2011 com 55 puérperas a maioria $(85,4 \%)$ das entrevistadas não possuía ocupação externa à residência ${ }^{21}$. Em 2017 a 
maioria das participantes $(73,3 \%)$ contribuíam com a renda familiar ${ }^{22}$. Em estudo atual as participantes em sua maioria $(75,0 \%)$ são casadas e brancas (77,5\%), sendo $55,0 \%$ evangélicas e 37,5\% católicas. Entre elas 40,0\% eram mãe pela primeira vez, e todas as participantes realizaram consulta de pré-natal, em pesquisa de 2009 onde foram entrevistadas 50 mulheres que levaram seu recém-nascido para realizar o teste do pezinho $60,0 \%$ tinham um filho, e 80,0\% aviam realizado consulta de pré-natal ${ }^{20}$. Em 2017 foram entrevistadas 75 puérperas, $69,3 \%$ tinham apenas um filho ${ }^{22}$.

Literaturas científicas geralmente refere que Triagem Neonatal é sinônimo de Teste do Pezinho, o que evidencia uma confusão na definição desses termos assim como mostram ${ }^{21,23,24}$.

O teste do pezinho é um dos exames inclusos no Programa Nacional de Triagem Neonatal, que também abrange a triagem auditiva ou teste da orelhinha, a ocular ou teste do reflexo vermelho ou teste do olhinho, a triagem cardíaca ou oximetria de pulso ou teste do coraçãozinho e a do frênulo lingual ou teste da linguinha ${ }^{22}$.

As puérperas participantes dessa pesquisa em sua maioria conhecem apenas alguns dos exames que devem ser realizados no recém-nascido $(65,0 \%)$. O desconhecimento das mães decorre da falta de informação e também da dificuldade em assimilar as orientações recebida ${ }^{21}$. Em estudo similar onde foram avaliadas 40 puérperas quanto ao conhecimento sobre a finalidade da triagem neonatal, chegou a conclusão de que $65,0 \%$ das participantes conheciam a finalidade da triagem, e 35,0\% desconheciam seu objetivo, fato este que denota a importância das orientações que devem ser dispensadas a estas mães sobre o referido assunto, mesmo antes do nascimento do bebê, com enfoque ainda no prénatal ${ }^{5}$.

Em estudo atual a maioria as participantes disseram ter recebido informações sobre os exames a serem realizados no recémnascido, porém quando questionadas sobre os testes da linguinha e do coraçãozinho eles eram conhecidos por um menor número de participantes, assim como em estudo verificou que um número baixo de gestantes conhecem o Protocolo de Avaliação do Frênulo da Língua em bebês ${ }^{18}$. A alimentação e a comunicação podem ser prejudicadas diante de um frênulo lingual alterado, o diagnóstico precoce torna-se um importante caminho para a prevenção de problemas na amamentação, na mastigação, na deglutição e no desenvolvimento da fala, de forma a promover saúde nos bebês atendidos ${ }^{25}$. Conforme pesquisa $40,0 \%$ das entrevistadas disseram não ter recebido informações suficientes para compreender os objetos dos exames que devem ser feitos no recém-nascido. A desinformação pode influenciar negativamente na realização dos exames, comprometendo tanto o diagnóstico precoce quanto o início do tratamento e a sua continuidade $^{21.26}$. Este fato destaca a fundamental importância do enfermeiro em relação as informações fornecidas as mulheres durante o pré-natal, sendo o período ideal para informar sobre os exames ${ }^{5,21,23}$.

Quando questionadas quanto á forma de realizar 0 teste do pezinho $87,5 \%$ das participantes souberam falar corretamente, em quanto outras participantes confundiram o teste com a impressão plantar, o carimbo do pé do bebê ou não souberam falar como é feito. Também foi possível observar em 2007 que $85,0 \%$ dos participantes souberam descrever, $15,0 \%$ não demonstraram conhecimento de como é feito o teste na criança, mesmo quando - entrevistador perguntava de maneira simplificada ${ }^{1}$. Em 2011 a maioria das entrevistadas conheciam a forma que o teste é realizado ${ }^{5}$.

Em relação ao período ideal de realização do teste do pezinho $80,0 \%$ das entrevistadas responderam que do terceiro ao sétimo dia de vida é o período ideal para coleta. Segundo pesquisa feita em 2011 ao serem indagadas sobre a idade recomendada para realização do teste do pezinho, $42,8 \%$ das puérperas não souberam informar ${ }^{21}$. Já em pesquisa feita em 2017, apesar de não saber o período adequado, a maioria das participantes $(85,9 \%)$ levou seu filho para realizar o teste entre o terceiro e o sétimo dia de vida, conforme preconizado pelo Ministério da Saúde ${ }^{22}$.

No que se refere à finalidade do teste do pezinho um expressivo número associou à descoberta de doenças no recém-nascido, porém não sabiam definir ou especificar quais as doenças que são triadas através do exame ${ }^{5,21,22}$. No presente estudo, a finalidade do teste era conhecida por $57,5 \%$ das participantes, porém um grande número de puérperas relacionou sua finalidade com sequelas decorrente as doenças detectadas quando não tratada.

A maioria das puérperas participantes $(92,5 \%)$ associou o teste do pezinho à descoberta de doenças e à realização de tratamento, assim como em 2017, as puérperas investigadas destacaram a importância do teste do pezinho para detectar doenças para as quais 
há tratamento ${ }^{22}$. Já em pesquisas realizadas também em 2017 e 2011 ambas relatam que um pequeno número de pais associaram o teste à descoberta de doenças e à realização de tratamento, a maioria não referiram a importância da descoberta precoce e o caráter preventivo de sequelas, nem a melhora da qualidade de vida da criança ${ }^{21,26}$.

O teste do reflexo vermelho, embora seja considerado exame simples, merece atenção durante sua realização pois o examinador precisa verificar cautelosamente as características do reflexo ${ }^{27}$. $O$ teste não tem por objetivo visualizar a retina e suas estruturas, mas sim verificar se existe algum obstáculo à chegada da luz até esta retina, é possível então detectar catarata, hemorragias, opacidade da córnea ou até mesmo tumores como retinoblastoma ${ }^{28}$. Em pesquisa de 2011 chegou ao resultado onde a maioria das puérperas $(60,2 \%)$ já ouviram falar sobre o teste do olhinho, porém, questionadas sobre a serventia do teste, $56,9 \%$ das entrevistadas disseram que não sabiam para que serve o teste e $38,9 \%$ responderam de forma errada. Chama a atenção 0 fato de que somente 4,2\% têm conhecimento da sua real importância ${ }^{29}$. Em estudo atual $37,5 \%$ das puérperas não sabiam a finalidade do exame, $15,0 \%$ responderam de forma errada, $47,5 \%$ tem conhecimento para que o exame deve ser feito.

O programa de Triagem Auditiva Neonatal é vinculado ao projeto Detecção Precoce da Deficiência Auditiva Infantil e atende usuários do Sistema Único de Saúde. Faz parte da rotina informar as mães sobre a Triagem Auditiva Neonatal ${ }^{14}$. Em 2008 foi realizado pesquisa onde encontrou os seguintes resultados, $77,3 \%$ das participantes conceituaram a Triagem neonatal auditiva adequada e $85,3 \%$ afirmaram serem suficientes as informações oferecidas ${ }^{14}$. Em estudos realizados com 413 gestantes observou que $68,7 \%$ delas nunca ouviram falar sobre o teste da orelhinha, $97,3 \%$ não possuíam conhecimento de como o teste é feito, $79,5 \%$ não recebeu informação alguma sobre 0 desenvolvimento da audição no bebê, $74,1 \%$ desconhece o período ideal de realização do teste $^{19}$. Em pesquisa de 2012, 15\% dos participantes não tiveram conhecimento a respeito da existência da Triagem neonatal auditiva em nenhum momento, $24 \%$ souberam da triagem auditiva na alta hospitalar, 22\% durante a internação, $12 \%$ depois da alta hospitalar, $4 \%$ antes da internação, e as demais famílias (23\%) não souberam informar ${ }^{30}$. As puérperas desse estudo em sua maioria
$(57,5 \%)$ sabiam qual a finalidade do teste da orelhinha.

Foi possível observar que a grande maioria $(80,0 \%)$ das participantes não tem conhecimento sobre a finalidade e nem como é feito o teste da linguinha, assim como mostra pesquisa de 2018, apenas $18 \%$ das participantes já ouviram falar sobre o assunto, a maioria não tem conhecimento sobre a finalidade (93\%), não conhecem o período de realização (92\%) e nem sobre o procedimento de frenotomia $(92 \%)^{18}$. O conjunto de características anátomo-funcionais relacionado com as funções de sucção e deglutição leva ao diagnóstico da limitação do movimento da língua causada pelo frênulo lingual ${ }^{16}$.

As participantes desse estudo apresentaram pouco conhecimento sobre o teste do coraçãozinho. Resultado semelhante foi encontrado em 2018 onde $100 \%$ das gestantes e $75 \%$ das puérperas entrevistadas não conheciam o teste, nem sua importância ${ }^{31}$. Durante 0 desenvolvimento embrionário, o coração e os vasos sanguíneos são os primeiros sistemas a se tornarem funcionais. $O$ sistema cardiovascular começa a ser desenvolvido no início da terceira semana gestacional, no $21^{\circ}$ ou $22^{\circ}$ dia o sangue passa a circular e o coração já começa a bater. A partir da quinta semana é possível auscultar os batimentos cardíacos fetais ${ }^{32}$. O teste do coraçãozinho faz parte da triagem neonatal do Sistema Único de Saúde (SUS) desde 2014 e deve ser realizado de forma universal. É um teste que busca triar os recém-nascidos com Cardiopatias Congênitas Críticas, realizando diagnóstico precoce e encaminhando ao tratamento em tempo hábil, favorecendo a redução da morbimortalidade neonatal ${ }^{33}$. CONCLUSÃO

Os resultados obtidos por esta pesquisa
apontam uma baixa compreensão das puérperas acerca da Triagem Neonatal. A maioria das participantes relataram ter recebido informações sobre os exames que devem ser feitos no recém-nascido. Porém quando questionadas sobre cada um deles, apenas $25,0 \%$ souberam elencar quais são; $40,0 \%$ das entrevistadas relataram não ter recebido informações suficientes durante o pré-natal.

Entre os exames da Triagem Neonatal o teste do pezinho foi o exame ao qual apresentaram maior conhecimento, conheciam a forma como o teste é realizado, o período ideal para coleta, e o que deve ser feito em caso de alterações. A finalidade do teste era conhecida por $57,5 \%$ das entrevistadas, sendo possível observar que uma grande parte das 
participantes desconheciam sua finalidade. Quanto aos testes do olhinho e da orelhinha a maioria das entrevistadas já tinham ouvido falar sobre eles, porém suas finalidades eram conhecidas por poucas. Já os testes da linguinha e do coraçãozinho são os testes mesmo conhecidos, poucas das entrevistadas já tinham ouvido falar sobre eles, e desconheciam sua finalidade.

Concluímos então que a maioria das puérperas deste estudo não tem conhecimento quanto a Triagem Neonatal. Apresentam informações muito superficiais acerca dos exames, mostrando o quanto é importante que o enfermeiro e a equipe multiprofissional trabalhem esse tema com as gestantes em cada consulta de pré-natal, esclarecendo o significado e a importância da Triagem Neonatal.

REFERÊNCIAS

1. Garcia MG, Ferreira EAP, Oliveira FPS. Análise da compreensão de pais acerca do Teste do Pezinho. Rev bras crescimento desenvolv hum. 2007;17(1):1-12.

2. Brasil. Lei n. 8.069, de 13 de Julho de 1990. Dispõe sobre o Estatuto da Criança e do Adolescente e dá outras providências. Diário Oficial da União [Internet] 16 jul. 1990. [acesso 2019 nov. 18] Disponível: http://www.planalto.gov.br/ccivil_03/leis/18069

3. APAESP. Teste do pezinho: um direito dos brasileiros. APAESP, SP. [acesso 2019 nov. 18] Disponível em: http://www.apaesp.org.br/ptbr/teste-do-pezinho/profissionais-desaude/Paginas/otestedopezinho.aspx.

4. Brasil. Ministério da Saúde. Triagem Neonatal Biológica Manual técnico. Brasília: Ministério da Saúde; 2016.

5. Abreu IS, Braguini WL. Triagem neonatal: o conhecimento materno em uma maternidade no interior do Paraná, Brasil. Rev Gaúcha Enferm. 2011;32(3):596-601.

6. Brasil. Secretaria de Estado da Saúde de São Paulo, ago. 2015. [Internet] Manual de acompanhamento da criança. [acesso 2019 nov. 18]. Disponível em:http://www.saude.sp.gov.br/resources/ses/p erfil/gestor/homepage/programa-de-

fortalecimento-da-gestao-da-saude-no-estadode-sao-paulo/consultas-

publicas/manual_de_acompanhamento_da_cri anca.pdf.

7. Aguiar Adriana Sousa Carvalho de, Cardoso Maria Vera Lúcia Moreira Leitão, Lúcio Ingrid Martins Leite. Teste do reflexo vermelho: forma de prevenção à cegueira na infância. Rev bras enferm. 2007;60(5):541-45.

8. Celino MBL. Nível de conhecimento sobre o teste do olhinho. Campina Grande: Núcleo de
Pesquisa e Extensão (Nupex); 2011.

9. Departamentos de Cardiologia e Neonatologia da SBP. Diagnóstico precoce de cardiopatia congênita crítica: oximetria de pulso como ferramenta de triagem neonatal. [Internet]. 2011[acesso 2019 nov. 18] Disponível em: https://www.sbp.com.br/fileadmin/user_upload/ 2015/02/diagnostico-precoce-oximetria.pdf.

10. Brasil. Ministério da Saúde. Departamento de Gestão e Incorporação de Tecnologias em Saúde da Secretaria de Ciência, Tecnologia e Insumos Estratégicos - DGITS/SCTIE [Internet]. Comissão Nacional de Incorporação de Tecnologias no SUS (CONITEC) - Relatório $n^{\circ}$ 115. Teste do coraçãozinho (oximetria de pulso) na triagem neonatal [acesso 2019 nov. 19]. Disponível em: http://conitec.gov.br/images/Incorporados/Teste Coracaozinho-FINAL.pdf

11. Brasil. Lei $n^{\circ} 12.303$, de 02 de ago. de 2010. Dispõe sobre a obrigatoriedade de realização do exame denominado emissões otoacústicas evocadas, Brasília, DF. [Internet] ago. de 2010. [acesso 2019 nov. 19]. Disponível em: http://www.planalto.gov.br/ccivil_03/_Ato20072010/2010/Lei/L12303.htm.

12. Silva Alessandra Aparecida da, Bento Daniela Veronese, Silva Laysa Nathália Favacho Barbosa. Ocorrência dos indicadores de risco para a deficiência auditiva em um centro de saúde do Rio Grande do Sul. Audiol Commun Res. 2018;23:e1919.

13. Brasil. Ministério da Saúde. Secretaria de Atenção à Saúde Departamento de Ações Programáticas Estratégicas. Diretrizes de atenção da triagem auditiva neonatal, Brasília, DF [Internet]. 2012 [acesso 2019 nov. 19] Disponível em: http://bvsms.saude.gov.br/bvs/publicacoes/diret rizes_atencao_triagem_auditiva_neonatal.pdf.

14. Tochetto TM, Petry T, Gonçalves MS, Silva ML, Pedroso FS. Sentimentos manifestados por mães frente à triagem auditiva neonatal. Rev. CEFAC. 2008;10(4):556-71.

15. Brasil. Presidência da República. Lei № 13002 de 20 de junho de 2014. Obriga a realização do protocolo de avaliação do frênulo da língua em bebês. Diário oficial da união, Poder Legislativo, Brasília, DF. 2014.

16. Martinelli RLC, Marchesan IQ, Berretin-Felix G. Protocolo de avaliação do frênulo lingual para bebês: relação entre aspectos anatômicos e funcionais. Rev. CEFAC. 2013;15(3):599-610

17. Agostini OS. Teste do linguinha, Brasília, DF[Internet]. set. de 2014[acesso 2019 nov. 20]. Disponível em: https://www.sbfa.org.br/fono2014/pdf/testelingui nha_2014_livro.pdf.

18. Pomini MC, Bordin D, Martins PRD, Twany DJ, Fadel CB, Alves FBT. Conhecimento de 
gestantes sobre 0 teste da linguinha em neonatos. Rev odontol. UNESP. 2018;47(6):341-47

19. Hochnadel DB. Conhecimento das gestantes sobre a triagem auditiva neonatal [monografia]. Porto Alegre: Universidade Federal do Rio Grande do Sul; 2011.

20. Salles M, Santos IM. O conhecimento das mães acerca do teste do pezinho em uma unidade básica de saúde. Rev Pesq: Cuidado é Fundamental Online. 2009;1:59-64.

21. Santos EC, Gaíva MAM, Santos JG, Abud SM. O conhecimento de puérperas sobre a triagem neonatal. Cogitare Enferm. 2011;16:282-88.

22. Arduini GAO, Balarin MAS, Silva-Grecco RL, Marqui ABT. Conhecimento das pessoas sobre o estes do pezinho. Rev paul pediatr. 2017; 35(2):151-57.

23. Amorim J, Souza M. O conhecimento das mães acerca da triagem neonatal. Rev Enferm UERJ. 2005;13:27-31.

24. Oliveira JG, Sandrini D, Costa DC, Serradilha AF, Parro MC. Triagem neonatal ou teste do pezinho: conhecimento, orientações e importância para a saúde do recém-nascido. CuidArte Enferm. 2008;2:71-6.

25. Souza CB, França EC, Alves ILF, Machado JP. Implantação do teste da linguinha no Centro De Referência em Saúde Auditiva/Cresa/Puc Goiás. Fragmentos de Cultura. 2014;24(esp): 51-6.

26. Mendes CA, Guigen AP, Anastácio-Pessan FL, Dutka JCR, Lamônica DAC. Conhecimento de pais quanto a triagem neonatal, contribuição do website Portal dos Bebês - Teste do pezinho. Rev CEFAC. 2017;19(4):475-83.

27. Aguiar ASC, Ximenes LB, Lúcio IML, Pagliuca LMF, Cardoso MVLML. Associação do reflexo vermelho em recém-nascidos com variáveis neonatais. Rev Latino-Am. Enfermagem. 2011;19(2):309-16.

28. Ledesma F, Zarpelon R, Xavier C, Smolarek A, Souza W, Mascarenhas L. Teste do reflexo vermelho: quando deve ser aplicado e qual benefício oferece? Arq Catarin Med. 2018;47(2):204-11.

29. Gonçalves LG, Oliveira MEBG, Almeida MHV, Abreu TT. Nível de conhecimento sobre o teste do olhinho, Campina Grande: Cesed; 2011

30. Alvarenga KF, Gadret JM, Araújo ES, Bevilacqua MC. Triagem auditiva neonatal: motivos da evasão das famílias no processo de detecção precoce. Rev soc bras fonoaudiol. 2012;17(3):241-47.

31. Aguiar CB, Jesus LC, Alves DM, Araújo AJ, Araújo IS, Oliveira GR, et al. Teste do coraçãozinho: importância da oximetria de pulso em neonatos para detecção precoce de cardiopatias. REAS - Rev Eletr Acervo Saúde. 2018; 12:S1349-S1357
32. Ferreira LM, Reis JM, Castro MDS, Costa MDS. O teste de triagem neonatal de cardiopatias congênitas: uma tecnologia de cuidado de enfermagem. Academus Rev Científica Saúde. 2016;1(1)

33. Costa JRB. Conhecimento dos enfermeiros sobre o teste do coraçãozinho [monografia]. Ariquemes (RO): FAEMA; 2018.

\section{CONFLITO DE INTERESSES}

Os autores declaram não haver conflitos de interesse AUTOR PARA CORRESPONDÊNCIA

\section{Larissa Brazolotto Ferreira}

Curso de Enfermagem

Universidade Paulista (UNIP) campus Araçatuba,

R. Baguaçu, 1939 - Jardim Alvorada,

16018-555 Araçatuba - SP, Brasil

E-mail: larissabrazolotto@hotmail.com 